\title{
The History Augmented Solow model
}

\author{
Carl-Johan Dalgaard* and Holger Strulik ${ }^{\dagger}$ \\ Leibniz Universitat Hannover, Discussion Paper No. 460
}

ISSN 0949-9962

November 2010

\begin{abstract}
Unified growth theory predicts that the timing of the fertility transition is a key determinant of contemporary comparative development, as it marks the onset of the take-off to sustained growth. Neoclassical growth theory presupposes a take-off, and explains comparative development by variations in (subsequent) investment rates. The present analysis integrates these two perspectives empirically, and shows that they together constitute a powerful predictive tool vis-a-vis contemporary income differences.

Keywords: Comparative Development; Unified Growth Theory; Neoclassical Growth Theory.

JEL: O11, O57.
\end{abstract}

\footnotetext{
${ }^{*}$ University of Copenhagen, Department of Economics, Øster Farimagsgade 5, building 26, DK-1353 Copenhagen K, Denmark; email: carl.johan.dalgaard@econ.ku.dk.

${ }^{\dagger}$ University of Hannover, Wirtschaftswissenschaftliche Fakultät, Königsworther Platz 1, 30167 Hannover, Germany; email: strulik@vwl.uni-hannover.de.
} 


\section{INTRODUCTION}

One of the biggest questions in social science is why some countries are more developed than others. A good place to start thinking about an answer, from an economics angle, remains the seminal Solow (1956) model. As shown by Mankiw, Romer and Weil (1992), and by many since, the basic Solow model holds considerable explanatory power vis-a-vis contemporary income differences. Yet, it leaves much income variation unexplained, which has led to various "augmentations" involving schooling (Mankiw, Romer and Weil, 1992; Ram, 2007), R\&D (Nunnemann and Vanhout, 1996) and health and longevity (Knowles and Owen, 1995).

Another strand of literature argues, however, that in order to better understand comparative development one must also understand the take-off to sustained growth, which separates an epoch of stagnation from the current regime where (many) countries grow persistently in terms of income per capita (Galor and Weil , 2000; Lucas, 2002; Hansen and Prescott, 2002; Galor and Moav, 2002). Hence, this literature - often referred to as "unified growth theory" - provides the mechanics of economic development before and after the take-off to growth (see Galor, 2005 for a survey). From the perspective of unified growth theory, neoclassical growth theory, which only analyzes the growth process once it has begun, is therefore an incomplete basis for an understanding of comparative development. A fuller understanding is arguably achieved by recognizing that a large fraction of contemporary income differences is due to the differential timing of the take-off itself (See Galor, 2010a). Theoretically, this critical historical turning point is hypothesized to be narrowly connected to the demographic transition; the fertility transition, specifically. ${ }^{1}$

The onset of the fertility transition stimulates subsequent growth in labor productivity for two major reasons: $(i)$ by lowering population growth it reduces the extent of capital dilution, (ii) by stimulating human capital accumulation it drives growth directly, but also indirectly via technological innovation. $^{2}$

The present paper demonstrates empirically that the combination of these two literatures delivers a powerful predictive tool. In its simplest version, the basic Solow model along with a control for the timing of the fertility transition accounts for about $70 \%$ of the cross-country variation in GDP

\footnotetext{
1The demographic transition generally involves two seperate transitions: a mortality transition and the fertility transition. The mortality transition often (but not always) precedes the fertility transition generating the familiar hump shaped trajectory for population growth.

${ }^{2}$ The fertility transition also leads to temporarily faster growth of the labor force relative to the total population which stimulates growth in income per capita (but not per worker).
} 
per worker in 2000. Moreover, the well known "anomaly" when estimating the parameters of the empirical Solow model - that the capital share is estimated to be exceedingly high - is eliminated.

The link between the timing of the fertility transition and contemporary labor productivity is robust to a range of controls for early institutional developments, cultural variables, geography and climate as well as early levels of technological sophistication. However, we also demonstrate that the partial correlation between the fertility transition and labor productivity is eliminated if we control for the channels through which the transition (in theory) should affect the growth process: capital dilution and human capital accumulation.

The paper proceeds as follows. In the next Section we lay out the empirical framework, and explain how we integrate insights from unified growth theory with the basic neoclassical growth framework in a simple way. Section 3 provides the empirical analysis, and Section 4 concludes.

\section{Empirical FramewOrk}

Figure 1 provides a stylized account of contemporary income differences. One reason why income differences may arise is found in the timing of the take-off, as described by unified growth theory. The figure illustrates a situation were one country experiences an early take-off at time $t_{1}$, which puts it on a positive growth trajectory. Meanwhile another country has not taken off at all (as yet); the "no take-off" scenario. Naturally, if we compare the income difference between these two countries at (say) time $t_{2}$ the difference in income would mainly be due to the differential timing of the take-off.

But the timing of the take-off is probably not the full story. For instance, Japan did not move onto a sustained growth trajectory until sometime during the 20th century, and yet it is today richer than many Western European countries that went through the transition in the 19th century. The combination of high investment rates, and the process of catch-up is a compelling explanation. Indeed, it is the standard textbook account, which involves the use of the neoclassical growth model. Figure 1 illustrates this possibility; a country that takes off at $t_{2}>t_{1}$ may either partially catch up with the early take-off group, or even overtake them. The overtaking phenomenon would reflect different (investment) behavior post take-off.

Hence, whereas unified growth theory explains how comparative development is affected by the difference in timing of take-off (i.e., $t_{1}-t_{2}$ ), neoclassical growth theory provides a complementary explanation as to the growth process after the take-off, which relates to the location of the steady 
Figure 1: Stylized Comparative Development

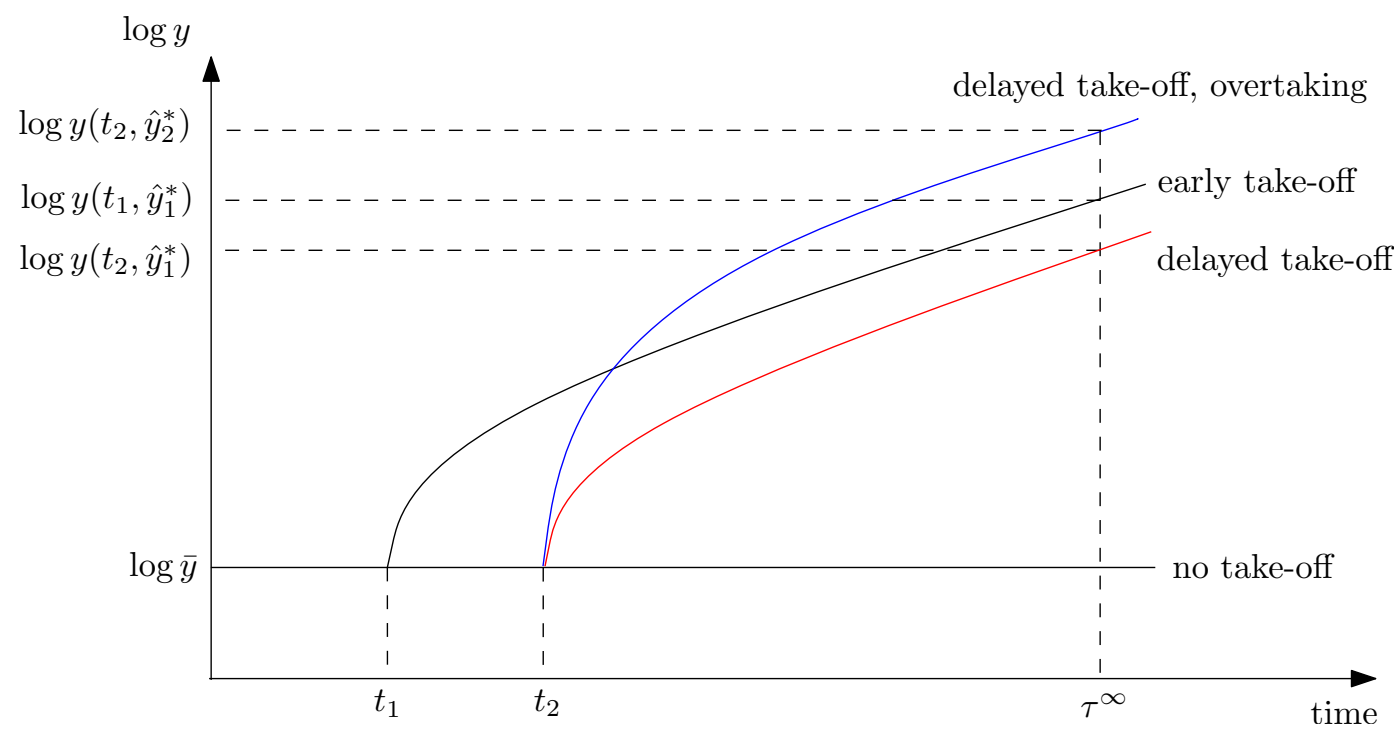

state growth trajectory. ${ }^{3}$ One might expect that the combination of the two theories would be a powerful vehicle for an understanding of comparative development.

In order to capture these considerations a bit more formally, consider the following law of motion for income per efficiency unit of labor, as it would follow from a Solow model:

$$
\log \left(\hat{y}_{t}\right)=\left[1-e^{-\lambda t}\right] \log \left(\hat{y}^{*}\right)+e^{-\lambda t} \log \left(\hat{y}_{0}\right)
$$

where $\hat{y}^{*}$ and $\hat{y}_{0}$ is steady state and initial income per efficiency unit of labor, respectively. The parameter $\lambda(>0)$ is the rate of convergence to steady state. Income per efficiency unit of labor is given as $\hat{y} \equiv Y /(A L)$, with $Y$ being GDP, $L$ the labor force (thus income per worker, $y \equiv Y / L$ ) and $A$ is the level of "technology". The model above describes an economy which has started growing as of time "0". But when is $t=0$ exactly? A simple answer could be: the year of the take-off. ${ }^{4}$

Hence, suppose the "Solow dynamics" began operating at time $\tau$; i.e., "take-off" occurred in year $\tau$. We now have

$$
\log \left(\hat{y}_{t}\right)=\left[1-e^{-\lambda(t-\tau)}\right] \log \left(\hat{y}^{*}\right)+e^{-\lambda(t-\tau)} \log \left(\hat{y}_{\tau}\right)
$$

\footnotetext{
${ }^{3}$ Of course, unified growth theory also speaks to the post take-off period. But from an empirical angle the Solow model (so far) provides more structure, which is useful for present purposes.

${ }^{4}$ Naturally, in practice, there is probably no such thing as "the year" of the take-off. The process is gradual and initially accelerating (e.g., Phillips and Sul, 2009). Hence, this is a simplistic representation designed to deliver an regression equation, the results from which are amendable to interpretation.
} 
Next, use that $\log \left(\hat{y}_{t}\right)=\log \left(y_{t}\right)-\log \left(A_{t}\right)$ and assume $\log \left(A_{t}\right)-\log \left(A_{\tau}\right)=g(t-\tau)$. In the long run $(t \rightarrow \infty)$ we are then left with the following expression for (long-run) income per worker $\left(y_{t}^{*}\right)$ :

$$
\log \left(y_{t}^{*}\right)=\log \left(\hat{y}^{*}\right)+g(t-\tau)+\log \left(A_{\tau}\right)
$$

This equation demonstrates how neoclassical growth theory as well as unified growth theory jointly contribute to an understanding of contemporary comparative development.

The first term on the right hand side of equation (1) is the neoclassical contribution, reflecting the level of steady state income. According to the Solow model, it may be further written:

$$
\log \left(\hat{y}^{*}\right)=\frac{\alpha}{1-\alpha}[\log (s)-\log (n+\delta+g)]
$$

where $s$ is the investment rate in physical capital, $n$ is the rate of population growth, $\delta$ is the rate of capital depreciation and $g$ is the trend level of technological change.

The contribution from "history" is found in the two other terms on the right hand side of equation (1): the timing of the take-off, $t-\tau$, and the initial level of technological sophistication at the eve of take-off, $A_{\tau}$ (rather than at "time 0"). Accordingly, conditional on post take-off growth determinants ( $s$ and so forth) we expect countries to be richer the longer its been since the economy underwent the "industrial revolution", and the more sophisticated the country was technologically at the time. ${ }^{5}$

Before we move on, it is useful to observe how equation (1) speaks to the conceptualization of contemporary income differences in Figure 1. In the depicted illustration a collection of the countries are on their - parallel - balanced growth paths when $t$ becomes "large", whereas another country (group of countries) is stuck in stagnation. It it clear that the implied income variation at this juncture is attributable to both factors that influence the location of the steady state growth path and factors that influence whether the process has begun at all. That is, the observed cross sectional variation in income $\left(\log \left(y\left[t_{2}, \hat{y}_{2}^{*}\right]\right)-\log (\bar{y})\right)$ is partly due to "neoclassical factors" (that influence $\left.\hat{y}_{2}^{*}\right)$ and partly due to the difference in timing of the take-off $t_{2}$. More generally, the fact that $A_{\tau}$ enters into equation (1) implies that even though two countries may have identical $\hat{y}^{*}$ they do not necessarily attain the same growth path; if one were more technologically sophisticated initially this effect will linger, as illustrated in Figure 1. This is the "decomposition" that equation (1) captures.

\footnotetext{
${ }^{5}$ Considerable variation in technological sophistication, prior to the take-off, is not inconsistent with limited pre take-off variation in GDP per worker. In a pre-take off environment changes in technology would be expected to manifest itself in changes in population density, but not in sustained increases in living standards; see Ashraf and Galor (2010) for theory and evidence. See Comin el al. (2010) for evidence that early technological sophistication (pre 1500) seems highly correlated with contemporary income differences.
} 
Combining equations (1) and (2) we are left with the following equation:

$$
\log \left(y_{t}^{*}\right)=\frac{\alpha}{1-\alpha}[\log (s)-\log (n+\delta+g)]+g(t-\tau)+\log \left(A_{\tau}\right)
$$

In order to take this equation to the data a few issues need to be addressed up front.

The first is how to measure time passed since the take-off; $t-\tau$. Based on the literature on unified growth theory, the timing of the fertility transition should be a good proxy (Galor, 2010b).

The second issue is how to think about " $g$ "; the underlying rate of technology growth. We will assume that once a take-off is achieved the country taps into the world technology frontier. Hence, $g$ can be viewed as exogenously given, from the perspective of the individual country. ${ }^{6}$ As a result, $g$ is common across countries in the sample which means that we can think of it as a parameter to be estimated (though see footnote 7 below).

The third issue relates to the neoclassical controls: $n$ in particular. Empirically, peak population growth rates, during the demographic transition, vary considerably across countries (e.g., Reher, 2004; Strulik, 2008). As a result, even conditional on the transition occurring, we expect differences in average growth rates of the labor force, post transition. We proxy post transition labor force growth by 1960-2000 growth rates. Similarly, $s$ is to be thought of as average investment in physical capital, post transition.

A final issue is how to deal with $\log \left(A_{\tau}\right)$. The simplest approach, of course, is to follow Mankiw et al. (1992) and assume the level of productivity is subject to random variation. Indexing countries by $i$ this would imply $\log \left(A_{i \tau}\right)=\log \left(\bar{A}_{\tau}\right)+\epsilon_{i}$. For our baseline regressions we also invoke a slightly more reasonable approach by assuming $\log \left(A_{\tau}\right)$ is subject to systematic regional variation, but random variation within regions. Denoting regions (Sub-Saharan Africa, South Asia etc) by $R$ this would mean $\log \left(A_{R i \tau}\right)=\log \left(A_{R \tau}\right)+\epsilon_{i}$. This can be handled in a cross-sectional context by adding regional fixed effects to the right hand side of the regression equation. For the robustness checks we push the matter a little further.

In sum the regression equation to be estimated below is

$$
\log \left(y_{i}\right)=\beta_{0}+\beta_{1} \log \left(s_{i}\right)+\beta_{2} \log \left(n_{i}+\delta+g\right)+\beta_{3}(t-\tau)_{i}+\mathbf{x}_{i}^{\prime} \gamma+\epsilon_{i}
$$

where $\mathbf{x}_{i}$ contains regional fixed effects and alternative confounders to be discussed below.

The history augmented Solow model holds several strong predictions, which we test below.

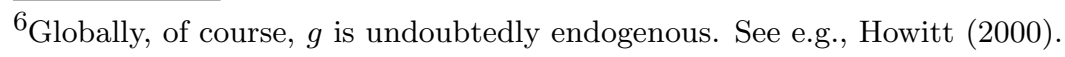


- The predictions that $\beta_{1}>0, \beta_{2}<0$ and $\beta_{3}>0$

- The restriction that the coefficient on $\log (s)$ and $\log (n+\delta+g)$ is numerically identical: $\beta_{1}$ $+\beta_{2}=0$

- The prediction that $\beta_{1}=-\beta_{2}$ is between 0.5 and $2 / 3$; this mirrors that $\alpha$ - capital's share - is expected to be between $1 / 3$ and 0.4 .

- The prediction that $\beta_{3}$ should capture the frontier productivity growth rate in the sample; a reasonable prior for this rate is about 2 percent on account of the growth trajectory of the US economy (arguably the technological leader) during the 20 th century. $^{7}$

\section{REGRESSION ANALYSIS}

3.1. Data and Baseline results. We estimate the history augmented Solow model in two samples, following the approach of Mankiw et al. (1992). The first sample only excludes oil producing nations, whereas the second sample excludes both major oil producers and "small nations" (with less than two million in population).

An additional sample limitation is that we exclude all countries from our sample that went through the fertility transition in 2000. This ensures that the year of the fertility transition is predetermined from the perspective of GDP per worker in 2000; our dependent variable of choice. Hence, this sample restriction implies that equation (3) can be said to characterize all countries in our sample as of the year 2000. A final motivation is that Reher (2004), the source of our data on the timing of the fertility decline, assigns the year 2000 to countries that so far have not undergone the fertility transition. In the present context we would naturally introduce unnecessary measurement error if we use these observations. By requiring that the transition occurs before 2000 they are automatically excluded.

The Appendix provides details on our data sources, and Table 1 reports summary statistics for our main variables. Investment rates and growth in the labor force are calculated as averages for the period 1960-2000; on average the fertility transition occurred in 1961. In our maximum (non oil) sample we have 109 observations.

\footnotetext{
${ }^{7}$ Alternatively, one could assume that $g$ varies. For example, suppose individual countries are visualized as gradually converging towards their technological steady state, as in the model by Nelson and Phelps (1966). Then $g$ would exhibit country specific variation in transition; in the long run, however, all countries would converge to the frontier rate. In this case the interpretation of $\beta_{2}$ changes from the unique "frontier rate" to the average growth rate in the country sample (see e.g., Zellner, 1969). Again one would think that $2 \%$ might be a reasonable prior as the global distribution of income seems to have remained fairly stable during the second half of the 20th century, which suggests that the frontier and average expanded at roughly similar rates (Acemoglu and Ventura, 2003).
} 
Table 1: Summary Statistics of Main Variables

\begin{tabular}{lcccc}
\hline \hline variable & mean & stdev & $\min$ & $\max$ \\
\hline $\log (y)$ in 2000 & 9.21 & 1.16 & 6.96 & 11.11 \\
$\log (s)$, avg. 1960-2000 & -2.06 & 0.58 & -3.74 & -0.8 \\
$\log (n+\delta+g)$, avg. 1960-2000 & -2.65 & 0.15 & -3.17 & -2.33 \\
year of fertility decline & 1961 & 27.89 & 1865 & 1995 \\
\hline \hline
\end{tabular}

109 Observations.

Before we turn to the results it is worth considering what the prospects are for identification. In order for OLS to deliver unbiased estimates the right hand side variables need to be orthogonal to the residual, which structurally should contain information about the level of technology at the time of take-off.

As discussed in Mankiw et al. (1992), the independence between $s, n$ and the level of $A$ is plausible. Based on unified growth theory it is also plausible to assume that the timing of the fertility transition is largely orthogonal to the (pre take-off) level of $A$; rather, it is the (expected) growth rate that might trigger the fertility decline (Galor, 2010b). In these respects the key orthogonality conditions are plausible. Of course, the residual $\epsilon_{i}$ may also contain other productivity determinants that might be correlated with both $s, n$ and the timing of the fertility decline; institutions for instance. Hence, omitted variable bias cannot be ruled out a priori. We return to this issue in Section 3.2 below.

Table 2 reports our baseline results. The first four columns refer to the "non oil" sample, whereas the last four columns concern the more limited sample where we also exclude countries with less than 2 million inhabitants.

In column 1 we test the unrestricted baseline Solow model in the "full sample". The sign of the included variables (average investment rate, $s$, and average growth in the labor force, $n$ ) are as expected, and the basic specification accounts for some $40 \%$ of the cross-country variation in GDP per worker in 2000. Moreover, the structural prediction of the coefficients being the same in absolute value cannot be rejected on neither the full sample nor the more limited sample (see bottom of column 1 and 5, respectively). Hence, in the remaining we employ the restricted model where the coefficients are required to be the same in absolute value.

The restricted model is estimated in column 2 and 6 , from which we can elicit information about the size of the structural parameter, $\alpha$. Theoretically $\alpha$ should reflect the capital share in national accounts and thus fall somewhere in an interval from $1 / 3$ and 0.4 . However, as is familiar from the Mankiw et al. (1992) study, the parameter is estimated to be much higher at about 0.6. 


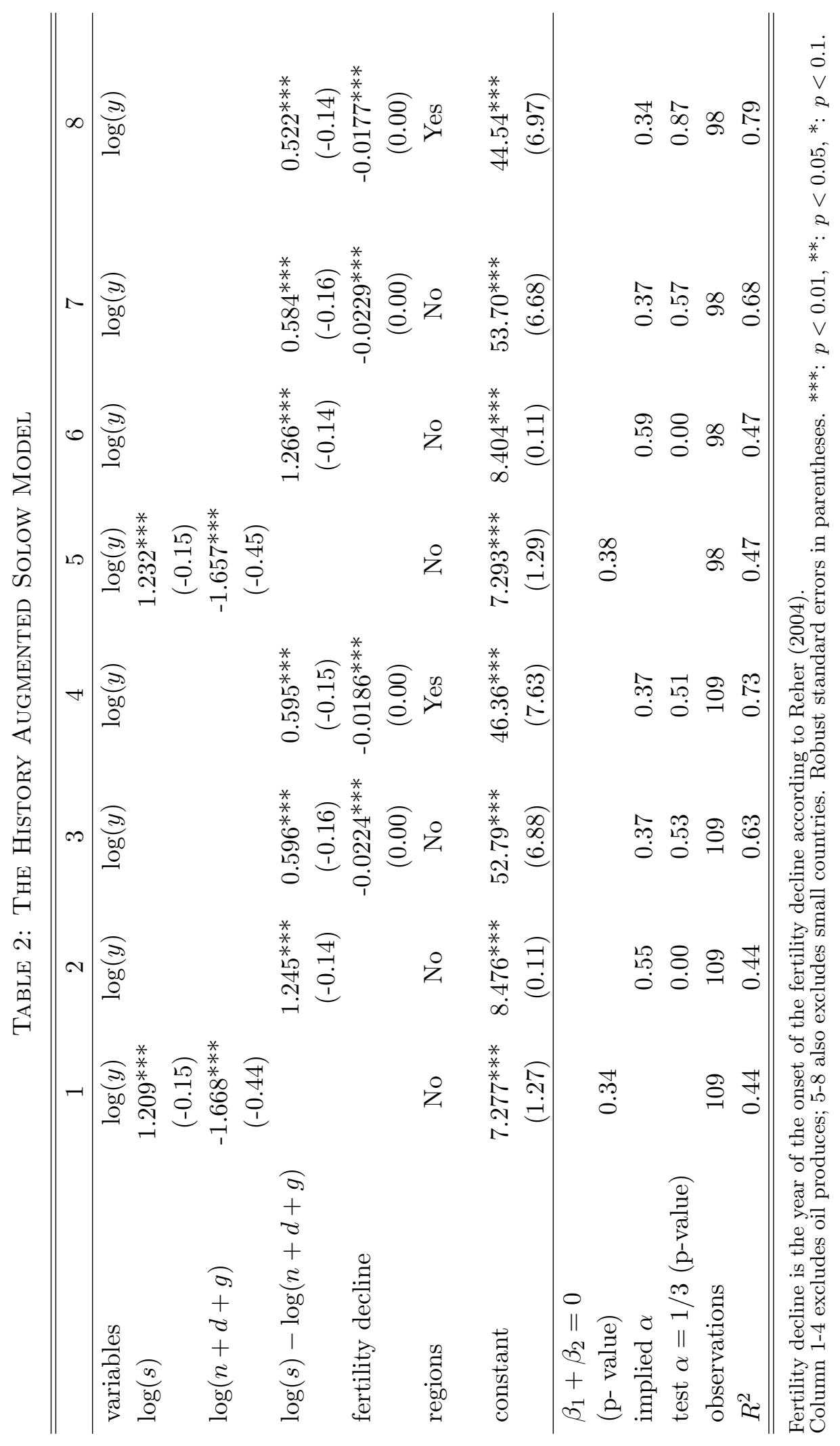


In columns 3 and 7 we include the year of the fertility transition. Several results are worth noting. First, the year of the fertility transition is highly significant in statistical terms and contributes significantly to the overall $R^{2}$, which rises to between 0.6 (column 3) and 0.7 (column 7).

Second, the parameter estimate is reasonable on a priori grounds; in both samples we obtain roughly -0.02 . Hence, each year the transition is delayed comes (on average) at a cost of roughly $2 \%$ lower GDP per worker in 2000. While this number matches expectations on structural grounds it is worth spelling out its implications. From Table 1 we know that there is a lot of variation in the timing of the fertility decline; the mean is 1961, but the standard deviation is roughly a generation (i.e., about 30 years). If each year "costs" 2 percent lost output per worker, a one standard deviation's worth of delay lowers GDP per worker in 2000 by nearly $50 \%$.

The third noteworthy result is that the "anomaly" detected originally by Mankiw et al. (1992) and recovered in column 2 and 6 , is eliminated; the estimated share of capital is close to $1 / 3$ economically as well as statistically (see bottom of column 3 and 7 for a formal test).

As a final check in our baseline setting we add regional fixed effects to control for systematic regional variation in the level of $A$. The results are largely unaffected by their inclusion except that the $R^{2}$ rises, which reflects that the fixed effects do strengthen the explanatory power of the model; the $R^{2}$ rises to between 0.7 (column 4) and 0.8 (column 8).

The baseline results leave some clue as to the relative importance of the timing of the take-off and the forces emphasized by neoclassical growth theory (cf. the discussion in Section 2), in accounting for cross-country inequality in labor productivity. When calculating the standardized regression coefficients associated with the "neoclassical term" and the fertility transition we obtain 0.31 for the neoclassical term, and 0.46 for the fertility transition (not shown in the table). The corresponding numbers for the more limited sample are: 0.28 and 0.45 .

These results should be interpreted with care. We are employing OLS estimation for which reason our estimates may be biased. But taken at face value our findings suggests that the forces emphasized by unified growth theory are somewhat more powerful than those traditionally emphasized by neoclassical growth theory.

3.2. The History Augmented Solow Model: Robustness. A natural question to ask at this stage is if the significance of the fertility decline can be attributed to omitted variable bias. There are four natural candidate confounders: Institutions, culture, geography and the initial level of technological sophistication. 
The first three categories of variables constitute "fundamental determinants" of productivity (see Acemoglu, 2009, Ch. 4). These factors likely influence a variety of allocations; e.g., savings rates, labor supply and more. In the present context one may worry that they also influence macro economic efficiency (i.e., " $A$ ") on the one hand, and correlate with the timing of the fertility decline on the other. ${ }^{8}$ Consequently, it is important to check whether their inclusion in the regression model eliminates the influence from the fertility decline.

In the analysis above we already attempted to control for the last potential confounder: initial technology. However, one may worry that there is country level variation left in the residuals that could bias our results, despite the theoretical prior of independence between the level of $A$ and the timing of the fertility decline. We will examine each of these potential confounders in turn. ${ }^{9}$

It is clear that examining whether the results can be ascribed to the influence from institutions faces a challenge: institutional quality is (partly) determined by human capital, which in theory is determined by the timing of the fertility decline. Consequently, adding measures of contemporary institutions would not allow for a discriminatory test, since these (in part) are an outcome from a process which may have begun with the fertility transition. ${ }^{10}$

Instead we begin by adding a measure of early institutions; executive constraints in 1900, which is used as a measure of early property rights institutions in e.g. Acemoglu et al. (2001). In our non-oil sample only three countries are recorded as undergoing the fertility transition before 1900 (Hungary, Sweden and Uruguay). As a result, if executive constraints in 1900 eliminates the significance of the year of the fertility decline one may argue that the correlation between the latter and contemporary income likely is spurious.

As seen from Table 3, when executive constraints are added the point estimate for the fertility transition is in fact reduced. But the year of the fertility decline remains economically significant as well as statistically significant at the $5 \%$ level (much like the institutional variable itself). The empirical fit is good; when institutions are added to the model it accounts for $90 \%$ of the variation in GDP per worker within the 43 country sample.

In an effort to explore the issue further, we follow the strategy suggested in Andersen et al. (2010), where clusters of proposed determinants of institutions are added as a proxy for early institutions.

\footnotetext{
${ }^{8}$ Indeed, they may be determinants of the timing of the fertility decline. See Galor (2010a) and Andersen et al. (2010). ${ }^{9}$ In the regressions to follow we focus on the non-oil sample in the interest of brevity; the results from the smaller country sample are similar and available upon request.

${ }^{10}$ For instance, Glaeser and Saks (2006) document that human capital accumulation have worked to lower corruption in the US. See also Glaeser et al. (2004).
} 
Table 3: The History Augmented Solow Model: Robustness Checks

\begin{tabular}{|c|c|c|c|c|c|c|}
\hline & 1 & 2 & 3 & 4 & 5 & 6 \\
\hline VARIABLES & $\log (y)$ & $\log (y)$ & $\log (y)$ & $\log (y)$ & $\log (y)$ & $\log (y)$ \\
\hline $\log (s)-\log (n+d+g)$ & $\begin{array}{c}0.354^{* *} \\
(0.162)\end{array}$ & $\begin{array}{c}0.537^{* * *} * \\
(0.173)\end{array}$ & $\begin{array}{c}0.485^{* * *} \\
(0.155)\end{array}$ & $\begin{array}{c}0.550^{* * *} \\
(0.159)\end{array}$ & $\begin{array}{c}0.505^{* * *} \\
(0.158)\end{array}$ & $\begin{array}{c}0.24 \\
(0.204)\end{array}$ \\
\hline Fertility decline & $\begin{array}{c}-0.0116^{* * *} \\
(0.00318)\end{array}$ & $\begin{array}{c}-0.0115^{* *} \\
(0.00512)\end{array}$ & $\begin{array}{c}-0.0146^{* * *} \\
(0.00344)\end{array}$ & $\begin{array}{c}-0.0169^{* * *} \\
(0.0039)\end{array}$ & $\begin{array}{c}-0.0154^{* * *} \\
(0.00413)\end{array}$ & $\begin{array}{l}-0.00776^{*} \\
(0.00414)\end{array}$ \\
\hline Executive constraint 1900 & $\begin{array}{c}0.140^{* * *} \\
(0.0349)\end{array}$ & & & & & \\
\hline Population density $1500(\log )$ & & $\begin{array}{c}-0.05 \\
(0.0683)\end{array}$ & & & & \\
\hline Frac. speaking Euro lang. & & $\begin{array}{c}0.461^{* *} \\
(0.184)\end{array}$ & & & & \\
\hline Legal origin: British & & & $\begin{array}{c}0.19 \\
(0.245)\end{array}$ & & & \\
\hline Legal origin: French & & & $\begin{array}{c}0.13 \\
(0.201)\end{array}$ & & & \\
\hline Legal origin: Socialist & & & $\begin{array}{c}-0.574^{* *} \\
(0.243)\end{array}$ & & & \\
\hline Legal origin: German & & & $\begin{array}{l}0.589^{*} \\
(0.307)\end{array}$ & & & \\
\hline Catholics (pct, 1980) & & & & $\begin{array}{c}0.004 \\
0.00273\end{array}$ & & \\
\hline Muslims (pct, 1980) & & & & $\begin{array}{c}0.0000384 \\
0.00262\end{array}$ & & \\
\hline Protestants (pct, 1980) & & & & $\begin{array}{c}0.005 \\
0.00371\end{array}$ & & \\
\hline $\mathrm{ELF}$ & & & & $\begin{array}{c}-0.001 \\
0.00265\end{array}$ & & \\
\hline Absolute Latitude & & & & & $\begin{array}{c}-0.01 \\
(0.00448)\end{array}$ & \\
\hline Tropical area & & & & & $\begin{array}{c}-0.24 \\
(0.272)\end{array}$ & \\
\hline Distance to coast or river & & & & & $\begin{array}{c}-0.305^{*} \\
(0.154)\end{array}$ & \\
\hline Primary enroll. rate (log, 1940) & & & & & & $\begin{array}{c}0.458^{* * *} \\
0.142\end{array}$ \\
\hline Regions & Yes & Yes & Yes & Yes & Yes & Yes \\
\hline Constant & $\begin{array}{c}31.89^{* * *} \\
(6.138)\end{array}$ & $\begin{array}{c}32.02^{* * *} \\
(10.02)\end{array}$ & $\begin{array}{c}38.55^{* * *} \\
(6.676)\end{array}$ & $\begin{array}{c}42.72^{* * *} \\
(7.709)\end{array}$ & $\begin{array}{c}40.71^{* * *} \\
(8.063)\end{array}$ & $\begin{array}{c}23.63^{* * *} \\
(8.134)\end{array}$ \\
\hline Observations & 43 & 94 & 109 & 107 & 105 & 72 \\
\hline R-squared & 0.9 & 0.77 & 0.77 & 0.74 & 0.78 & 0.77 \\
\hline
\end{tabular}

Robust standard errors in parentheses. ***: $p<0.01,{ }^{* *}: p<0.05, *: p<0.1$.

Accordingly in column 2 we introduce population density in 1500 (inspired by Acemoglu et al., 2002) and fraction of the population speaking one of the major European languages (inspired by Hall and Jones, 1999). This allows for a much bigger sample, as can be seen. Individually only the language variable is significant. The main result, however, is that the year of the fertility decline continues to be significant. The same is true if we add a full set of legal origin dummies, as seen 
from column 3, albeit these institutional proxies collectively exert significant influence on GDP per worker in 2000. Taken together these results suggest that the partial correlation between the year of the fertility decline and current labor productivity is robust to the inclusion of controls for early institutions.

The second check consists of adding controls that may be capturing cultural values and norms. In this regard we add three variables capturing religious beliefs (percent of population being Catholic, Protestant or Muslim, respectively) as well as ethnolinguistic fractionalization. As column 4 testifies these variables do not overturn the significance of the fertility transition either.

Another worry is that the results may be due to an intervening effect from geography or climate related circumstances. Accordingly, we augment the model (in addition to the regional fixed effect) by three controls that have been stressed in the empirical growth literature. First, absolute latitude, which is a catch-all climate control; second, distance to coast or river, capturing in particular trade costs; third, country area in the tropics. As seen from column 5, however, the inclusion of these controls does not overturn the significance of the year of the fertility decline.

Finally, we attempt to control more rigorously for the level of technology around the time of takeoff. So far we have allowed for regional variation in $A$, by way of regional fixed effects. As a final check, we assume that country level technology at the time of take-off systematically differed as a consequence of differential historical technology adoption rates (Comin et al., 2010). Naturally, we have no direct measure of historical $A$. But following Nelson and Phelps (1966) one may proceed to hypothesize that the variation in $A$ is explained by early human capital levels, $h_{\tau}$. According to this view we would have $\log \left(A_{R i \tau}\right)=\log \left(A_{R \tau}\right)+\log A\left(h_{i \tau}\right)+\epsilon_{i}$, where $\epsilon_{i}$ is remaining - unsystematic - country variation in $A_{R \tau}$, whereas $A\left(h_{i \tau}\right)$ (with $A^{\prime}>0$ ) is the human capital dependent rate of adoption at time $\tau$ and $A_{R}$ continues to be regional specific variation captured by regional fixed effects. We assume $A\left(h_{i \tau}\right)$ is log-linear.

In measuring early human capital levels, and thus "initial $A$ ", we employ primary school enrollment rates for 1940 from Benavot and Riddle (1988). Benavot and Riddle (1988) do produce data further back in time, and it would be attractive to use these earlier human capital data, as $25 \%$ of the countries in our (non oil) sample underwent the fertility transition before 1940. For these countries, schooling in 1940 is an outcome and, theoretically, partly a result of the fertility transition rather than an initial condition. However going back before 1940 limits the sample quite severely. Hence, 
in order to obtain as great a country coverage as possible we opted for 1940 (the latest year in their study), despite the before mentioned drawback. ${ }^{11}$

The results are given in Table 3 column 6. As expected, early school enrollment rates are highly significant. Moreover, their inclusion does reduce the size of the point estimate for the year of the fertility decline. In part this may simply be caused by the fact that the enrollment rates are measured post transition for a large number of countries. In spite of this, however, the year of the fertility transition remains significantly correlated with GDP per worker in 2000.

\subsection{The Fertility Transition and Current Labor Productivity: Exploring the Channels}

of Influence. In the regressions above we did not control for current human capital. The reason is that human capital accumulation is the key mechanism by which the fertility decline is supposed to matter to contemporary income. If contemporary human capital levels are included, the impact from the fertility decline should recede.

To see this more clearly, suppose investments in skills, $e$, starts expanding at the time of the take-off, $\tau$. This is a key prediction of unified growth theory, as declining fertility is argued to be associated with a substitution of quantity $(n)$ for quality (skills). If so, the skill investments at time $t$ can be written

$$
e(t)=e(\tau) e^{g_{e}(t-\tau)}
$$

where $e(\tau)$ are skill investments around the time of take-off; $g_{e}$ is thus the growth rate in skill investments between take-off and current day, $t$. If we assume, like Galor and Weil (2000), that the per worker level of human capital in the economy is a function of these investments, $h(t)=h[e(t)]$, the fertility transition should matter to labor productivity via its impact on $h$. Conversely, if we include measures of human capital in the regression, the correlation between the timing of the fertility transition and current labor productivity should disappear. In order to see that this must be the case, recall that the fertility transition - in theory - influences labor productivity in two separate ways.

The first pathway is through reduced capital dilution; with (gradually) slower population growth the capital-labor ratio is increased. However, in the regressions above we have already controlled for this channel, as our specification includes a control for the rate of labor force growth - post transition (i.e., proxied by labor force growth 1960-2000). As a result, the significance of the timing of the fertility transition above cannot be attributed to reduced capital dilution. The second pathway is

\footnotetext{
${ }^{11}$ Still, the results are qualitatively unaffected if we alternatively use enrollment rates as of 1900, 1910, 1920 or 1930.
} 
that by increasing human capital accumulation, GDP per worker is stimulated directly, and very likely indirectly via innovation (i.e., indirectly through $A$ ). Since we did not control for current human capital in the regressions above it is entirely possible that significance of the timing of the fertility decline is attributable to the human capital channel.

In order to assess whether this is the case or not, we invoke three measures of outcomes from (past and present) "quality investments": Average years of schooling in the population $(+15)$ in 2000, the average IQ score in the population and life expectancy at birth in 2000. All three variables can be viewed as proxies for $h(t)$, although the first is the most commonly used proxy. Hence, if an earlier timing of the fertility transition, by raising $e(t)$, has worked to elevate human capital levels we would expect to see its influence diminished upon the inclusion of either one of these three variables. The results from re-estimating our basic model - human capital augmented - are reported in Table 4.

All three "child quality variables" are highly significant correlates with GDP per worker. However, whereas average years of schooling and IQ scores eliminate the influence from the fertility transition (column 2 and 4 ) the same is not true for life expectancy (column 1). As can be seen from column 3 and 5, years of schooling and IQ render the fertility transition insignificant mainly due to a marked reduction in the point estimate on the latter; the coefficient associated with the fertility decline is reduced by $2 / 3$ or more when either the schooling variable or IQ is introduced.

These results are consistent with the main prediction of unified growth theory: the differential timing of the fertility transition is a strong determinant of current income levels due to its influence on the path of human capital accumulation.

At the same time there is cause for concern. As seen from Column 2, the estimated return on skills is very large: about $20 \%{ }^{12}$ In contrast, a conventional estimate from the "Mincer literature" would be half that (e.g., Caselli, 2005).

Recall, however, that the estimates from Table 4 likely encapsulates both the direct effect of human capital on productivity (which is what micro studies estimate) and the indirect effects via innovation. Such indirect effects may either result from the production of new ideas, as emphasized in the R\&D growth literature (e.g., Romer, 1990; Aghion and Howitt, 1992), or be the consequence of more rapid technology adoption (e.g., Nelson and Phelps, 1966, Benhabib and Spiegel, 2005).

\footnotetext{
${ }^{12}$ Implicitly, we are following conventions when adding human capital to the Solow model. That is, GDP per worker can be written: $y=k^{\alpha}(A h)^{1-\alpha}$. Human capital per worker, $h$, can be calibrated as $h=e^{\psi \cdot u}$, where $\psi$ is the return to an additional year of schooling, and $u$ is average years of schooling. Accordingly, in the (log linear) levels specification for GDP per worker, $\psi$ is a parameter to be estimated. See e.g., Romer (2001, Ch. 3).
} 


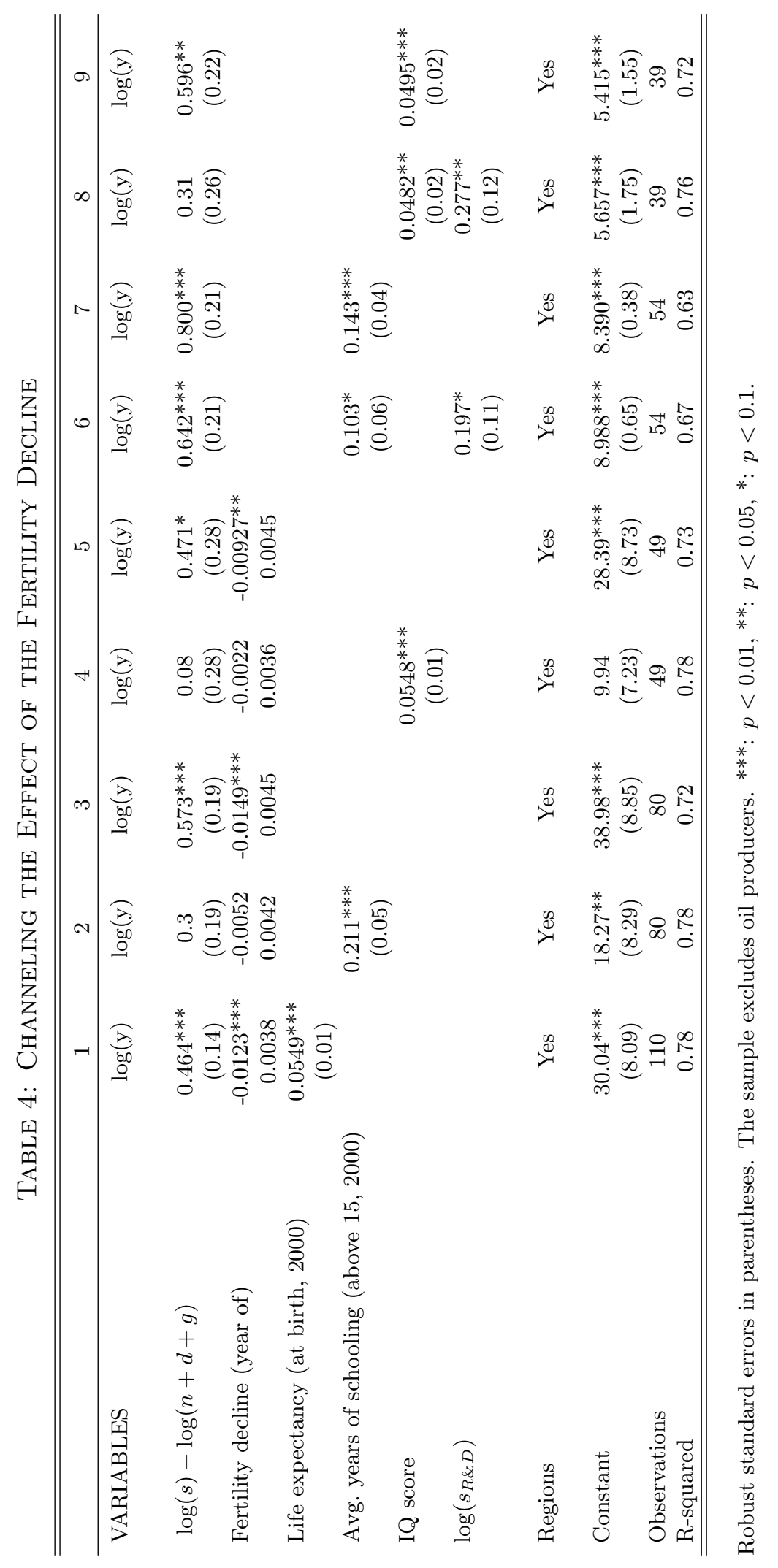


In order to check the viability of this explanation we introduce the R\&D investment rate. If indeed the large return on skills (recovered above) is attributable to the indirect effects of human capital on technology innovation or adoption, we expect to see it decline if the $R \& D$ investment rate is introduced, as the latter should pick up the innovation channel.

As seen from column 6, when R\&D investment (as a fraction of GDP) is added to the model the estimated return on schooling shrinks to about 10\%. To isolate the pure effect of introducing $R \& D$ investments we also provide the results form estimating the model without $R \& D$, but in the same sample (column 7); in this setting the estimated return is considerably higher at $15 \%$, as expected. Interestingly, however, the estimate for IQ does not change much; when the average IQ score increases by 1 it is associated with an increase in labor productivity of about $4 \%$ whether we control for R\&D or not.

Overall, the results from Table 4 paint a coherent picture. Early transition countries managed to start accumulating human capital sooner than late take-off countries. The resulting human capital divergence instigated divergence in livings standards. Hence, while the timing of the fertility decline is a key determinant of contemporary comparative development, its effect is operating through human capital and ideas; the more proximate sources of growth.

Finally, one may observe that the above results are fully consistent with the various augmentations of the Solow model that have been proposed (Mankiw et al, 1992; Ram, 2007; Knowles and Owen, 1995; Nunnemann and Vanhout, 1996). Yet it adds one important additional piece of information. Namely, that the origin of observed differences in these additional "capital stocks (be it schooling, IQ, life expectancy or technological "ideas") is found in the differential timing of the take-off to sustained growth, which is connected to the timing of the fertility transition.

\section{Concluding Remarks}

The present paper has augmented the empirical Solow model by taking into account the timing of the take-off to sustained growth. According to unified growth theory, the timing of the fertility decline should be a good proxy for the timing of the take-off to growth. We have shown theoretically how one can combine key insights from unified growth theory with the neoclassical model in a simple way.

Our baseline results are quite strong. We find that adding the timing of the fertility transition to the neoclassical growth model improves the empirical fit considerably. Taken together the timing 
of the fertility decline and (post take-off) investment and labor force growth can account for about $70 \%$ of the variation in GDP per worker; nearly $80 \%$ if one on top adds regional fixed effects. When we examine the standardized regression coefficients we find that the influence from the fertility transition is slightly greater than the influence from the "neoclassical determinants" of productivity.

Another key finding is that the obtained parameters square well with priors. The share of capital is estimated to be about 0.3 , and the point estimate for the fertility decline suggests that each year the transition is delayed lowers GDP per worker by about two percent. The latter is consistent with the view that once the take-off has occurred individual countries (on average) manage to tap into the "world technology frontier", thus experiencing a rate of underlying productivity growth similar to "leader nations' like the US, conditional on physical capital investments etc.

The influence from the fertility transition is robust to the inclusion of controls for institutions, culture, climate/geography and early human capital. But the partial correlation between the year of the fertility decline and current GDP per worker is eliminated if we control for the channels through which the fertility transition is supposed to affect contemporary comparative development: reduced capital dilution and human capital accumulation.

Admittedly, our regressions do not necessarily establish causality, although the obtained point estimates square well with priors. Hence, an important topic for future work is to obtain a clearer empirical understanding of the determinants of the fertility transition. This will eventually pave the way for a study where the causal impact from the fertility transition on global inequality in labor productivity can be assessed. 


\section{Appendix A. Data Sources}

Executive constraints in 1900: Polity IV (http://www.systemicpeace.org/polity/polity4.htm)

Fraction speaking a major European language: Hall and Jones (1999).

GDP per worker in 2000: Penn World Tables, 6.3. (Heston et al., 2009)

Growth in the Labor Force: Penn World Tables 6.3. (Heston et al., 2009)

Investment rates 1960-2000: Penn World Tabels 6.3 (Heston et al., 2009)

IQ: Jones and Schneider (2006)

Legal origin: Treisman (2007)

Life expectancy in 2000: World Development Indicators (http://data.worldbank.org/).

Population density in 1500: McEvery and Jones (1978)

Primary enrollment rates in 1940: Benavot and Riddle (1988)

Schooling in 2000 (average years): Barro and Lee (2001)

R\& D expenditures as a fraction of GDP, 2000: World Development Indicators (http://data.worldbank.org/).

Year of fertility decline: Reher (2004) 


\section{References}

Acemoglu, D., 2009. Introduction to modern economic growth. Princeton University Press

Acemoglu, D. and J. Ventura, 2003. The world income distribution, Quarterly Journal of Economics $117,659-694$.

Acemoglu, D., S. Johnson, and J.A. Robinson, 2001. The colonial origins of comparative development: An empirical investigation. American Economic Review 91, 1369-1401.

Acemoglu, D., S. Johnson, and J.A. Robinson, 2002. Reversal of fortune: geography and institutions in the making of the modern world income distribution. Quarterly Journal of Economics 117, $1231-1294$.

Aghion, P., and P. Howitt, 1992. A model of growth through creative destruction, Econometrica 60, $323-351$.

Andersen, T.B., C-J. Dalgaard and P. Selaya, 2010. Eye disease and development. Mimeo (University of Copenhagen).

Ashraf, Q, and O. Galor, 2010. Dynamics and Stagnation in the Malthusian Epoch. Forthcoming in American Economic Review

Barro, R.J. and J.W. Lee, 2000. International data on educational attainment: updates and implications. Oxford Economic Papers 53, 541-

Benhabib, J. and Spiegel, 2005. Human capital and technology diffusion, in (P. Aghion and S. Durlauf eds.) Handbook of Economic Growth, Amsterdam: North Holland, 935-966.

Benavot, A. and P. Riddle, 1988. The expansion of primary education, 1870-1940: Trends and Issues. Sociology of Education 61, 191-210.

Caselli, F., 2005. Accounting for Cross-Country Income Differences. In: Aghion P. and S. Durlauf (eds.) Handbook of Economic Growth.

Comin, D., W. Easterly and E. Gong, 2010. Was the wealth of nations determined in 1000 B.C.? American Economic Journal: Macroeconomics 2, 65-97.

Galor, O., 2005. From stagnation to growth: unified growth theory. in (P. Aghion and S. Durlauf eds.) Handbook of Economic Growth, Amsterdam: North Holland.

Galor, O., 2010a. The 2008 Lawrence R. Klein Lecture - Comparative economic development: insights from unified growth theory. International Economic Review 51, 1-44.

Galor, O., 2010b. The Demographic transition: causes and consequences. Working Paper (Brown University).

Galor, O. and D. Weil, 2000, Population, technology and growth: from Malthusian stagnation to the demographic transition and beyond, American Economic Review 90, 806-828.

Galor, O. and O. Moav, 2002. Natural selection and the origin of economic growth, Quarterly Journal of Economics 117, 1133-1191. 
Glaeser, E., R. La Porta, F. Lopez-de-Silanes and A. Schleifer, 2004. Do institutions cause growth? Journal of Economic Growth 9, 271-303.

Glaeser, E. and R. Saks, 2006. Corruption in America. Journal of Public Economics, 90, 1053-1072.

Hansen, G. and E. Prescott. 2002. Malthus to Solow. American Economic Review 92, 1205-17.

Hall, R. and C.I Jones, 1999. Why do some countries produce so much more output per worker than others? Quarterly journal of Economics 114, 83-116.

Heston, A. R. Summers and B. Aten, 2009. Penn World Table Version 6.3. Center for International Comparisons of Production, Income and Prices at the University of Pennsylvania.

Howitt, P., 2000. Endogenous growth and cross-country income differences. American Economic Review 90, 829-846.

Jones, G. and W.J. Schneider, 2006. Intelligence, human capital, and economic growth: A bayesian averaging of classical estimates (BACE) approach. Journal of Economic Growth 11, 71-93.

Knowles, S. and P.D. Owen, 1995. Health capital and cross-country variation in income per capita in the Mankiw-Romer-Weil model. Economics Letters 48, 99-106.

Lucas, R. E. Jr., 2002, "The industrial revolution: past and future", in: Lucas, R. E. Jr., lectures on Economic Growth, Cambridge, Massachusetts: Harvard University. Press.

Mankiw .N.G., D. Romer, and D.N. Weil, 1992. A contribution to the empirics of economic growth, Quarterly Journal of Economics 107 , 407-437.

McEvedy, C. and R. Jones, 1978. Atlas of World Population History. Penguin Books Ltd., New York, NY.

Nelson, R.R. and E.S. Phelps, 1966. Investment in humans, technological diffusion, and economic growth, American Economic Review 56, 69-75.

Nonneman W. and P. Vanhout, 1996. A further augmentation of the Solow model and the empirics of economic growth for the OECD. Quarterly Journal of Economics 111, 943-53.

Phillips, P.C.B. and D. Sul, 2009. Economic transition and growth, Journal of Applied Econometrics $24,1153-1185$

Ram, R., 2007. IQ and economic growth: further augmentation of Mankiw-Romer-Weil model, Economics Letters 94, 7-11.

Reher, D. S., 2004. The demographic transition revisited as a global process, Population Space and Place 10, 19-42.

Romer, P., 1990. Endogenous technological change, Journal of political Economy 98, 71-102.

Romer, D., 2001. Advanced Macroeconomics. McGraw Hill, New York.

Solow, R.M, 1956. A contribution to the theory of economic growth, Quarterly Journal of Economics 70, 65-94. 
Strulik, H., 2008. Geography, health, and the pace of demo-economic development. Journal of Development Economics 86, 61-75.

Treisman, D., 2007, "What have we learned about the causes of corruption from ten years of crossnational empirical research?" Annual Review of Political Science, 2007.

Zellner, A., 1969. On the aggregation problem: A new approach to a troublesome problem. In M. Beckmann and H.P. Künzi (eds.) : Economic Models, Estimation and Risk Programming Essays in honor of Gerhard Tintner". Springer Verlag, Berlin. 